\title{
Nutritional and Chemical-Physical Characterization of Fresh Pasta Gnocchi Prepared with Sea Water as New Active Ingredient
}

\author{
Gabriella Santagata ${ }^{1}$, Domenico Zannini ${ }^{1,+}+\mathbb{D}$, Salvatore Mallardo ${ }^{1,+}{ }^{\text {, Floriana Boscaino }}{ }^{2}$ and \\ Maria Grazia Volpe ${ }^{2, *(D)}$
}

1 National Research Council, Institute of Polymers, Composites and Biomaterials, Via Campi Flegrei 34, 80078 Pozzuoli, Italy; gabriella.santagata@ipcb.cnr.it (G.S.); domenico.zannini@ipcb.cnr.it (D.Z.); salvatore.mallardo@ipcb.cnr.it (S.M.)

2 Institute of Food Science, National Research Council, Via Roma 64, 83100 Avellino, Italy; floriana.boscaino@isa.cnr.it

* Correspondence: mgvolpe@isa.cnr.it; Tel.: +39-33885-45393

$\dagger$ These authors equally contributed to the work.

check for updates

Citation: Santagata, G.; Zannini, D.; Mallardo, S.; Boscaino, F.; Volpe, M.G. Nutritional and Chemical-Physical Characterization of Fresh Pasta Gnocchi Prepared with Sea Water as New Active Ingredient. Foods 2021, 10, 2585. https://doi.org/10.3390/ foods10112585

Academic Editor:

Verica Dragović-Uzelac

Received: 15 September 2021

Accepted: 22 October 2021

Published: 26 October 2021

Publisher's Note: MDPI stays neutral with regard to jurisdictional claims in published maps and institutional affiliations.

Copyright: (c) 2021 by the authors. Licensee MDPI, Basel, Switzerland. This article is an open access article distributed under the terms and conditions of the Creative Commons Attribution (CC BY) license (https:// creativecommons.org/licenses/by/ $4.0 /)$.
Abstract: This study shows the chemical-physical and nutritional results obtained using food-grade sea water for the preparation of fresh pasta Gnocchi with respect to those prepared with tap water. Gnocchi obtained by mixing the flour with seawater (GSW) were compared with traditional Gnocchi made with tap water (GTW). The contents of sodium chloride, macro and micro elements, volatile molecules profile, thermal properties, and morphological analysis were investigated in both Gnocchi types. The analysis of chlorides showed that the samples prepared with sea water had a significantly lower $\mathrm{NaCl}$ content after cooking in comparison with those prepared with tap water. These results were also confirmed by the inductively coupled plasma (ICP) analysis for sodium content. The profiles of the volatile molecules acquired by gas chromatography-mass spectrometry (GC-MS) evidenced significant differences between the groups of aromatic molecules of the two typologies of samples. Morphological analysis evidenced that both raw and cooked GSW Gnocchi were structurally tightened whereas GTW Gnocchi showed a labile and weak macromolecular network. In addition, GSW Gnocchi was more thermally stable than GTW Gnocchi, as evidenced by thermogravimetric analysis (TGA).

Keywords: Gnocchi; sea water; micro-macro elements; volatile profile; thermal properties; morphological analysis

\section{Introduction}

Gnocchi is a typically Italian culinary preparation, mainly used as a first course. In general, unless otherwise specified, the term "Gnocchi" identifies "those of potatoes". As with many other Italian specialties, there are as many variations of gnocchi as there are regions in Italy and Italian housewives. Gnocchi dates back to Roman times, and at that time it did not contain potatoes but was made of a porridge-like dough. The potato variety only came after the potato had taken its way to Europe [1].

Anyway, even though both are high in carbohydrates, regular pasta may have less effect on blood sugar levels. Nevertheless, it is important to note that this study compared plain potatoes to pasta-not Gnocchi, which are prepared by kneading potato, wheat, and eggs. Gnocchi contains a good share of protein and cooks very quickly in boiling water ( 2 to $3 \mathrm{~min}$ ). Served with various sauces (gorgonzola, butter and sage, tomato and parmesan, amongst the most famous), they became a very popular dish, even overseas, where Gnocchi are known almost as "pasta" when speaking of a classical Italian "primo piatto" [2]. Besides being tasty, gnocchi-type pastas are relatively easy to prepare and consume. However, like pastas, Gnocchi are also commonly cooked in salt-water and, after 
their recovery from water, they preserve about $10 \%$ in weight of salt. Several studies have highlighted a causal relationship between salt intake and blood pressure [3]. Randomized trials demonstrate that a lower salt intake is associated with a reduced risk of cardiovascular disease, all-cause mortality, and other conditions, such as kidney disease, stomach cancer, and osteoporosis $[4,5]$.

For the above reasons and in order to prepare a novel healthy and functional Gnocchi pasta type, keeping up the good natural flavor and taste, sea water has been substituted to tap water and used as an active ingredient of Gnocchi dough. The main characteristic of sea water is its ionic salt content [6]. Salinity indicates the quantity of salts dissolved in marine waters coming from the constant supply of substances from over land flowing rivers, submarine volcanoes, and decomposing marine organisms. Specifically, salinity measures the quantity of salt present in a kilogram of sea water; for ocean waters, it is around 35\% [7]. The use of sea water as a new active ingredient of Gnocchi formulation can enhance the chemical-nutritional properties of this kind of pasta by increasing the micro and macro elements and decreasing or completely eliminating the content of added salt since cooking is performed in unsalted boiling water; moreover, GSW higher thermal stability, the mineral content is preserved during and after gnocchi cooking.

Thus, the aim of this research was the formulation of Gnocchi using edible sea water in place of tap water and investigate the properties of fresh pasta (Gnocchi) prepared with edible sea water (GSW) and compare them with the ones of Gnocchi prepared with tap water (GTW). Specifically, the percentage content of sodium chloride, concentration of macro and micro elements content together with the volatile molecules profile were evaluated, compared, and discussed. In addition, the morphological analysis (SEM) of raw and cooked GSW and GTW cryogenically delaminated fractures was performed and the study of their thermal stability was assessed by thermogravimetric analysis (TGA).

\section{Materials and Methods}

Gnocchi samples were supplied by Pastificio Artigianale Leonessa, Via Don Minzoni 231, 80040 Cercola, Napoli, Italy. Sea water, produced from Abba Blu srl (San Sperate $\mathrm{CA}$, free of microorganisms and free of substances harmful for health, suitable for human consumption, in compliance with current legislation Italy), was kindly supplied from Asset srl Portici (NA), Italy. Gnocchi dough consisted of wheat flour 00, potatoes and tap water (identification code GTW) or food-grade sea water (identification code GSW).

\subsection{Gnocchi Cooking Process and Water Absorption}

In order to evaluate the properties of Gnocchi, specimens of GSW and GTW were dropped in unsalted boiling water for three minutes, gently recovered with a strained, allocated in Petri dishes, and left to dry at room temperature under a ventilated hood. In addition, GTW were also cooked in $10 \% w / v$ of salted water in order to reproduce the usual cooking methodology. The water absorption capacity of Gnocchi samples was determined after drying the samples in an oven until constant weight and the result was expressed as percentage water absorption.

Calculation formula:

$$
\% \mathrm{AW}=\mathrm{W}_{\text {after cooking }}-\mathrm{W}_{\text {before cooking }} / \mathrm{W}_{\text {before cooking }} \times 100
$$

where AW = Absorption water after cooking, $\mathrm{W}_{\text {after cooking }}=$ Gnocchi weight after cooking, $\mathrm{W}_{\text {before cooking }}=$ Gnocchi weight before cooking.

\subsection{Determination of the Sodium Chloride Content (the Mohr Method)}

Approximately $2 \mathrm{~g}$ of the raw and cooked GSW and GTW samples were kept in an oven at $105{ }^{\circ} \mathrm{C}$ until their constant weight was reached; then, the samples were soaked in $40 \mathrm{~mL}$ of water-ultratrace. Then, the solutions were stirred for $2 \mathrm{~h}$ at room temperature, centrifugated for $10 \mathrm{~min}$ at $4000 \mathrm{rpm}$, filtered in $50 \mathrm{~mL}$ volumetric flask, and made up to volume with water-ultratrace. The $\mathrm{pH}$ of the solution was adjusted with $0.1 \mathrm{~N}$ sodium 


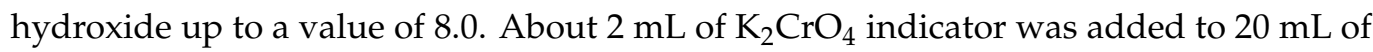
solution that was titrated with $0.1 \mathrm{~N}$ silver nitrate until endpoint. In parallel, a blank test was carried out by titrating $20 \mathrm{~mL}$ of distilled water with $0.1 \mathrm{~N}$ silver nitrate until endpoint in the presence of $2 \mathrm{~mL}$ of $\mathrm{K}_{2} \mathrm{CrO}_{4}$ indicator.

By knowing the stoichiometry and moles consumed at the end point, the amount of chloride was determined. From the milligrams of $\mathrm{Cl}^{-}$ion, the $\mathrm{mg}$ of $\mathrm{NaCl}$ of the sample is obtained.

\subsection{Mineralization of Samples and Determination of Micro-Macro Elements: Inductively Coupled Plasma-Optical Emission Spectrometers Analysis ICP-OES}

Gnocchi samples underwent acid digestion according to the method of Volpe et al. [8], slightly modified. Five milliliters of $\mathrm{HNO}_{3}$ and $2.5 \mathrm{~mL}$ of $\mathrm{H}_{2} \mathrm{O}_{2}$ were added to $0.5 \mathrm{~g}$ of dried sample. The mixture was digested at $240{ }^{\circ} \mathrm{C}$ until the solution became transparent, (Heating digester DK VELP Scientifica). After cooling, the solution was diluted with waterultratrace up to a final volume of $25 \mathrm{~mL}$ in a volumetric flask and microfiltrated. The clear and plain solution was analyzed with (ICP-OES). The elemental analysis of macro, micro, and trace elements was performed by ICP-OES with iCAP 7000 Series (Thermo Scientific, Waltham, MA, USA), equipped with ASX-520 autosampler (CETAC ${ }^{\mathrm{TM}}$ ). A calibration curve was constructed using a standard mix solution containing all analyzed elements. The final concentration of the elements was expressed as mg element $\mathrm{kg}^{-1}$ dry weight.

\subsection{Determination of Volatile Compounds by Solid Phase Microextraction Gas Chromatography/Mass} Spectrometer Analysis (SPME-GC/MS)

Volatile compounds of both raw and cooked GTW and GSW samples were determined by solid-phase micro-extraction (SPME) coupled to gas-chromatography/mass spectrometry (GC/MS), according to the modified method of Di Renzo et al. [9]. GTW and GSW samples were cut into pieces of $2-3 \mathrm{~mm}$. For each SPME analysis, $3 \mathrm{~g}$ of sample was placed in a $20 \mathrm{~mL}$ headspace vial. The sample was allowed to equilibrate at $40{ }^{\circ} \mathrm{C}$ for $5 \mathrm{~min}$ at $250 \mathrm{rpm}$ using the automatic sampling system Gerstel MPS2 (Gerstel GmbH \& Co., Mülheim, Germany). The analysis was conducted by a GC/MS system (Agilent 7890/5975 Inert, Agilent, Santa Clara, CA, USA) equipped with the above-mentioned autosampler with helium as carrier gas (1.5 mL/min). A coated Divinylbenzene/carboxen/Polydimethylsiloxane (DVB/CAR/PDMS) fiber (Sigma-Aldrich S.r.l., Milan, Italy) was exposed to the headspace of the sample for $30 \mathrm{~min}$ maintaining the sample at $40^{\circ} \mathrm{C}$. The fiber was desorbed for $10 \mathrm{~min}$ at $240{ }^{\circ} \mathrm{C}$ in the injection unit, in splitless mode. The separation was carried out in a capillary column HP Innowax (Agilent Technologies, Santa Clara, CA, USA) (30 m × 0.25 mm id. $\times 0.50 \mu \mathrm{m}$ film thickness). The GC oven temperature program started at $40{ }^{\circ} \mathrm{C}$ for $3 \mathrm{~min}$, then was ramped to $240{ }^{\circ} \mathrm{C}$ at $5{ }^{\circ} \mathrm{C} / \mathrm{min}$ and kept the final temperature for $10 \mathrm{~min}$. The mass spectrometer operated with an ion source at $230^{\circ} \mathrm{C}$, quadrupole temperature of $150{ }^{\circ} \mathrm{C}, 70 \mathrm{eV}$ electron energy, acquiring in TIC mode from m/z 33 to 300 uma. Identification of volatile compounds was achieved by comparing mass spectra with the Wiley library (Wiley7, NIST 05). The proportion of each compound was estimated by dividing its mean area by the total area of the chromatogram and expressed as a percentage. Blank experiments were conducted in two different modalities: blank of the fiber and blank of the empty vial. All the analyses were performed in duplicate.

\subsection{Thermogravimentric Analysis (TGA)}

Thermogravimetric analyses (TGA) were carried out with a Mettler Thermogravimetric Analyzer Mod. TG. Measurements were performed on samples of about 4-6 mg, placed in open ceramic crucibles, and heated from room temperature to $600{ }^{\circ} \mathrm{C}$ at $20{ }^{\circ} \mathrm{C} / \mathrm{min}$ in a nitrogen atmosphere, with a nominal gas flow rate of $30 \mathrm{~mL} / \mathrm{min}$. Before the tests, a blank curve was measured and subtracted from the single thermograms, to correct from instrumental drift [10]. 


\subsection{Scanning Electron Microscopy (SEM)}

Morphological analysis of both gnocchi after baking in tap and sea water and dried post-cooking residual fractions were carried out on cryogenically fractured surfaces by scanning electron microscopy (SEM) (Quanta 200 FEG, FEI, Eindhoven, The Netherlands) in high vacuum mode, using a secondary electron detector and an accelerating voltage of $20.0 \mathrm{kV}$. Before the electron microscopy observation, the fractured surfaces were coated with Au-Pd alloy with an SEM coating device (MED 020, Bal-Tec AG, Tucson, AZ, USA). The coating provided the entire sample surfaces with a homogeneous layer of metal of $18 \pm 0.2 \mathrm{~nm}$.

\subsection{Statistical Analysis}

The mean and standard deviation were calculated for each experimental parameter. Differences among the sample bread were determined for each volatile compound by analysis of variance (ANOVA), and the results were considered significant if the associated $p$ values were below 0.05 (Tanagra 1.4 software).

\section{Results}

\subsection{Water Absorption}

After cooking, Gnocchi samples prepared with tap and sea water exhibited low water absorption. This outcome was expected considering the drastic structural changing undergone by starch upon heating and following cooling. In fact, it is well known that chemically, starch is mostly composed of linear amylose and highly branched amylopectin, providing a native crystalline material [11,12]. When heated in water, starch granules undergo spontaneous destructurization; they become hydrated, swell, and are transformed into a paste. The granule structure collapses due to the melting of crystallites, unwinding of double helices, and breaking of hydrogen bonds. These changes are collectively referred to as starch gelatinization. On cooling, the disaggregated starch chains retrograde gradually into partially ordered structures of crystallites that differ from those in native granules [13]. Moreover, the starch molecules' re-crystallization increases over the cooling time. As a result, a labyrinth structure that blocks the water molecules' absorption occurs, because of the hydrophobic behavior of the crystalline zones that, backwards, are more prone to expel water from the crystalline zones. This outcome, widely accepted in the literature, can withstand the very low water absorption recorded for both Gnocchi samples [14].

Anyway, higher water absorption values were found for GTW samples $(+0.8 \%)$ as compared with GSW $(+0.1 \%)$. This can be related to the presence of micro and macro elements in sea water able to strengthen the already crystalline network formed upon cooling involving both carbohydrate and protein polar residues of the Gnocchi matrix [15]. As a consequence, the available water binding sites were strongly reduced and substituted by the ionic physical binding of salts and polar residues of macromolecular structures, as shown by Razzaq et al., in their similar investigation [16]. This hypothesis will be confirmed by the results of the thermal analysis, as following discussed.

\subsection{Evaluation of Sodium Chloride Content in Raw/Cooked GTW and GSW Samples}

The weight percentage of sodium chloride was evaluated on raw and cooked samples and the results are reported in Table 1. Firstly, it deserves highlighting that Gnocchi prepared with tap water and cooked in $10 \% \mathrm{w} / \mathrm{v}$ of salted water absorbed about $65 \%$ of $\mathrm{NaCl}$ in their edible network. Actually, chefs and pasta producers recommend using $10 \mathrm{~g}$ of salt per $100 \mathrm{~g}$ of pasta in $1 \mathrm{~L}$ of cooking water, since it is well known that salt enhances the food taste. If these indications are respected, the salt weight gain is certainly remarkable; usually, gnocchi prepared with tap water in the dough and cooked in salted water can absorb up to $3 \%$ by weight of $\mathrm{NaCl}$ [17]. Anyway, according to the World Health Organization (WHO), the consumption of sodium chloride must be decreased during the day to about a total of $4 \mathrm{~g}$ per individual, a hardly reached limit if considering that most hidden salt is ingested with packaged foods [18]. 
Table 1. $\mathrm{NaCl}$ content of raw and cooked GTW and GSW Gnocchi.

\begin{tabular}{ccc}
\hline Sample & \% NaCl Content & \% NaCl Gain (+), Losing (-) \\
\hline Raw GTW & 1.81 & - \\
GTW cooked in 10\% w/v salted water & 3.00 & +65.7 \\
GTW cooked in unsaltedWater & 0.50 & -72.4 \\
Raw GSW & 2.00 & - \\
GSW cooked in unsaltedWater & 1.40 & -30.0 \\
\hline
\end{tabular}

In order to decrease the intake of salt, it is advisable to strongly limit its use during home cooking; therefore the possibility of obtaining healthy dishes prepared with less amount of sodium chloride without renouncing to the excellent sensorial properties of mouthwatering delicacies could represent a beneficial output for consumers and an interesting scientific approach finalized to obtain increasingly healthy foods [19]. In addition, it is important to emphasize that the right flavor depends on several factors, such as the type of salt used, the type of pasta, and obviously the sensitivity of the consumers' taste buds [20]. Finalized to prepare palatable and healthy Gnocchi pasta type, sea water was used as an ingredient of dough and the following Gnocchi were cooked in unsalted tap water.

From the analysis of Table 1, it is worth highlighting that when Gnocchi are prepared in unsalted water, they partially release the starting salt content as there is a tendency to achieve a saline balance between the water and the Gnocchi, as expected. Thus, when salt is added to the water, the pasta must absorb it during the rehydration process and cooking, in a homogeneous and quantitatively correct way. If salt is not added to water, the internal salt of the Gnocchi will diffuse in the cooking water until salt absorption/desorption equilibrium is reached [17]. In fact, while GTW samples lost $72.4 \%$ of starting dough salt, GSW specimens released only $30 \%$ of $\mathrm{NaCl}$. This outcome could be ascribed to the strong physical network developed between the polar groups of starch and proteinbased components of Gnocchi (flour and potatoes) and the salts naturally available in sea water [21]. Indeed, it is likely that starch and protein carboxyl, amide, hydroxyl residues can develop ionic interactions with salt cations and hydrogen bonding, thus providing a tightened polymer-based structure responsible for the physical entrapment of $\mathrm{NaCl}$ in GSW samples [22]. It is not the case that these samples evidenced higher physical and thermal stability, demonstrated by both SEM and TGA analysis. Besides the above chemico-physical properties, Gnocchi prepared with sea water evidenced a greater content of beneficial macroelements, as discussed in the following section.

\subsection{Evaluation of Macro and Micro Elements of GTW and GSW Samples by ICP-OES Method}

In Table 2, GSW and GTW macro and micro element contents are detailed. All the measurements were performed in triplicate and the deviation standard for all the samples ranged between $0.01-0.08 \%$. It is worth underscoring that, except for sodium ions, all the macro-micro element concentrations were considerably higher in GSW samples; this outcome could be due to their significant presence in sea water physical binding with polar residues of both carbohydrate and protein residues inside Gnocchi dough. In fact, macro-micro elements could physically interact with potatoes amylopectin/amylose polar residues, as following demonstrated by morphological and thermal properties and widely reported in the literature [23].

Table 2. Macro-micro elements of GTW and GSW samples expressed in mg/kg.

\begin{tabular}{cccccccccc}
\hline Sample/Elements & Na & Ca & K & Mg & Fe & Cu & Sr & Zn & I \\
\hline GTW & 80 & 240 & 1870 & 285 & 11.735 & 2.179 & 1.970 & 11.130 & 0.010 \\
\hline GSW & 50 & 340 & 2500 & 700 & 17.690 & 2.905 & 4.607 & 14.095 & 0.041 \\
\hline
\end{tabular}


Potassium, calcium, and magnesium contribute to developing vital cell functions, particularly as heart excitability is concerned. They are key elements for myocardial movement and activation of enzymatic systems [24,25].

Calcium and magnesium results are higher than those reported by Nalepa et al. [26]. Magnesium is contained in many foods; however, about $80 \%$ of this metal is lost during food processing and as a consequence, a large percentage of people all over the world do not meet the minimum daily magnesium requirement [27]. This mineral activates several biochemical reactions all necessary for proper functioning of the human body. Magnesium has a role in controlling the transport of most minerals, including calcium, potassium, and sodium, in order to exploit their function such as nerve conduction, muscle contraction, and in maintaining heart rhythm [28].

Potassium is an essential mineral and also an electrolyte, mainly found in the intracellular fluid where it is the most important positive ionic strength and is required for normal cell function because of its role in maintaining intracellular fluid volume and transmembrane electrochemical gradients. Along with sodium, it regulates the right heartbeat to tune and stabilize the blood pressure, tunes the metabolism of carbohydrates and proteins, stimulates the elimination of toxic residues in the body [29]. Zinc and copper are essential elements for the human body and they result in chronic and acute effects in case of their deficiency [30]. About $99 \%$ of Zinc is intracellular while the rest is in plasma. The function of zinc in cells and tissues is dependent on metallic proteinase and these enzymes are associated with reproductive, neurological, immune, dermatological systems. It is essential for normal spermatogenesis and maturation, genomic integrity of sperm, for normal organogenesis, proper functioning of neurotransmitters, proper development of the thymus, proper epithelialization in wound healing, taste sensation, secretion of pancreatic and gastric enzymes [31]. Copper plays a very important role in human metabolism particularly because it allows many critical enzymes to function properly. In human blood, copper is principally distributed between the erythrocytes and in the plasma. In erythrocytes, $60 \%$ of copper occurs as copper-zinc metallic-enzyme superoxide dismutase [32].

The iron concentrations were lower than those reported by Al-Mussali and Al-Gahri [33], while zinc concentrations resulted higher. Finally, as expected, the Iodine content was significantly higher in GSW samples. Iodine is an important micronutrient element and is required for the synthesis of thyroid hormones regulating several important physiological processes. In fact, an iodine-deficient diet causes a wide spectrum of illnesses, including goiter and mental retardation. The possibility of iodine oral intake with Gnocchi could represent a valid method to enrich the diet of this element [34,35]. These data suggested that Gnocchi prepared with food sea water (GSW) could represent a healthy and nutrient functional food able to increase the uptake of essential macro-micro nutrients.

Finally, $\mathrm{Cd}$ and $\mathrm{Pb}$ concentrations were minor of $0.005 \mu \mathrm{g} \mathrm{kg}^{-1}$ for all samples, showing no environmental contamination [36,37].

\subsection{Evaluation of Volatile Compounds by HS-SPME-GC/MS Analysis}

Forty-four volatile organic compounds (VOCs) belonging to various chemical classes, were identified through SPME-GC/MS and reported in Table 3. The main compounds belonged to eight classes, aldehydes (13), ketones (10), alcohols (7), furans (3), acids (10), terpenes (4), esters (1), and phenols (2). Notwithstanding there are few available studies concerning the organoleptic quality of gnocchi and in general fresh pasta and, in particular, very poor data on flavor characterization. Some studies suggest that VOCs pasta might be affected by raw ingredients flavors (e.g., flour, potatoes, water) and by the different processing phases, such as blending, forming, packaging, and storage [38-40]. On the other hand, the VOCs of Gnocchi pasta might derive from sugar microbial metabolism that enhances by the addition of water during mixing and dough formation phases, as (alcohols, 2,3-butanedione, 3-hydroxy-2-butanone, esters, and acids), and by enzymatic oxidation or autoxidation of fatty raw materials (e.g., aliphatic aldehydes, ketones, acids and alkylfuran). The aldehydes were the most represented volatile molecules in the headspace of gnocchi 
samples and increased during cooking. In detail, the compound hexanal was the most abundant aldehyde in all gnocchi samples investigated; while aldehydes and ketones increase during cooking; instead, alcohols, furans, and acids decrease with cooking. During the cooking process, the starch-lipid, probably included as complexes with amylose may be released, becoming susceptible to thermal oxidation, and although the enzymes (e.g., lipoxygenase and hydroperoxidase lyase) involved in the production of aldehydes are heat denatured, the high temperatures accelerate autoxidation, a process that does not require enzymatic catalysis [38]. In accordance with some authors, in general, increases in aldehydes and ketones during handling and cooking processes are associated with a decrease in the content of alcohol and ester compounds. The loss of alcohol compounds can be due to the high solubility of alcohols in water an effect greatly enhanced by the cooking process because of the large volume of water employed [40,41]. The terpenes compounds might derive from raw ingredients. There is no evidence in the literature on the influence of water origin (SW and TW) on the production of volatile compounds in gnocchi samples.

Table 3. Volatile organic compounds (VOCs) identified by SPME-GC/MS in Gnocchi samples.

\begin{tabular}{|c|c|c|c|c|}
\hline Sample/Elements & $\begin{array}{l}\text { Raw } \\
\text { GTW }\end{array}$ & $\begin{array}{l}\text { Raw } \\
\text { GSW }\end{array}$ & $\begin{array}{c}\text { GTW } \\
\text { Cooked in Unsalted } \\
\text { Water }\end{array}$ & $\begin{array}{c}\text { GSW } \\
\text { Cooked in Unsalted } \\
\text { Water }\end{array}$ \\
\hline \multicolumn{5}{|l|}{ Aldehydes } \\
\hline 2-methylbutanal & $0.54 \pm 0.02$ & $1.09 \pm 0.02$ & $1.17 \pm 0.02$ & $0.21 \pm 0.01$ \\
\hline 3-methylbutanal & $1.10 \pm 0.07$ & $2.11 \pm 0.28$ & $1.71 \pm 0.02$ & $1.96 \pm 0.08$ \\
\hline Pentanal & $2.69 \pm 0.14$ & $\mathrm{Nd}$ & $2.93 \pm 0.38$ & $1.55 \pm 0.06$ \\
\hline $\begin{array}{l}\text { Hexanal } \\
\text { Octanal }\end{array}$ & $56.31 \pm 0.31$ & $14.28 \pm 0.03$ & $66.36 \pm 0.50$ & $39.88 \pm 1.53$ \\
\hline 2-heptenal & $0.31 \pm 0.01$ & $1.12 \pm 0.00$ & $\mathrm{Nd}$ & $3.64 \pm 0.16$ \\
\hline Nonanal & $\mathrm{Nd}$ & $\mathrm{Nd}$ & $\mathrm{Nd}$ & $3.34 \pm 0.08$ \\
\hline 2-octenal & $2.33 \pm 0.04$ & $5.11 \pm 0.15$ & $3.51 \pm 0.09$ & $6.51 \pm 0.18$ \\
\hline decanal & $\mathrm{Nd}$ & $\mathrm{Nd}$ & $\mathrm{Nd}$ & $0.94 \pm 0.0$ \\
\hline Benzaldehyde & $\mathrm{Nd}$ & $\mathrm{Nd}$ & $\mathrm{Nd}$ & $2.13 \pm 0.01$ \\
\hline Tot & $1.98 \pm 0.07$ & $5.07 \pm 0.09$ & $3.51 \pm 0.02$ & $5.87 \pm 0.28$ \\
\hline \multicolumn{5}{|l|}{ Ketones } \\
\hline 2-Propanone & $3.52 \pm 0.07$ & $2.63 \pm 0.22$ & $2.23 \pm 0.09$ & $5.85 \pm 0.42$ \\
\hline 2,3-butanedione & $\mathrm{Nd}$ & $1.33 \pm 0.01$ & $\mathrm{Nd}$ & $\mathrm{Nd}$ \\
\hline 2-heptanone & $\mathrm{Nd}$ & $2.45 \pm 0.10$ & $\mathrm{Nd}$ & $3.02 \pm 0.03$ \\
\hline 1-hepten-3-one & $\mathrm{Nd}$ & $\mathrm{Nd}$ & $0.47 \pm 0.02$ & $\mathrm{Nd}$ \\
\hline Acetoin & $\mathrm{Nd}$ & $1.69 \pm 0.00$ & $0.84 \pm 0.02$ & $2.05 \pm 0.08$ \\
\hline 2,3-octanedione & $0.17 \pm 0.00$ & $\mathrm{Nd}$ & $0.34 \pm 0.03$ & $\mathrm{Nd}$ \\
\hline 6-methyl-5-hepten-2-one & $0.22 \pm 0.00$ & $0.49 \pm 0.02$ & $0.27 \pm 0.04$ & $0.77 \pm 0.04$ \\
\hline 3,5-octadien-2-one & $0.61 \pm 0.01$ & $2.04 \pm 0.10$ & $1.07 \pm 0.03$ & $2.54 \pm 0.08$ \\
\hline 3-octen-2-one & $\mathrm{Nd}$ & $\mathrm{Nd}$ & $0.55 \pm 0.02$ & $\mathrm{Nd}$ \\
\hline Tot & $4.52 \pm 0.07$ & $10.62 \pm 0.23$ & $5.77 \pm 0.09$ & $14.23 \pm 0.63$ \\
\hline \multicolumn{5}{|l|}{ Alcohols } \\
\hline 1-Pentanol & $3.92 \pm 0.13$ & $4.68 \pm 0.14$ & $3.05 \pm 0.18$ & $4.00 \pm 0.15$ \\
\hline 1-Hexanol & $3.56 \pm 0.00$ & $6.42 \pm 0.14$ & $2.43 \pm 0.01$ & $5.77 \pm 0.15$ \\
\hline 3,5-octadien-2-ol & $0.36 \pm 0.01$ & $\mathrm{Nd}$ & $0.23 \pm 0.01$ & $\mathrm{Nd}$ \\
\hline 1-octen-3-ol & $1.20 \pm 0.05$ & $1.73 \pm 0.02$ & $1.36 \pm 0.10$ & $1.49 \pm 0.03$ \\
\hline Benzenemethanol & $\mathrm{Nd}$ & $0.58 \pm 0.01$ & $\mathrm{Nd}$ & $\mathrm{Nd}$ \\
\hline Tot & $9.22 \pm 0.15$ & $13.58 \pm 0.26$ & $7.07 \pm 0.06$ & $11.26 \pm 0.02$ \\
\hline \multicolumn{5}{|l|}{ Furans } \\
\hline 2-methylfuran & $0.52 \pm 0.00$ & $4.90 \pm 0.08$ & $\mathrm{Nd}$ & $\mathrm{Nd}$ \\
\hline 2-ethylfuran & $1.49 \pm 0.02$ & $3.93 \pm 0.14$ & $1.33 \pm 0.05$ & $2.09 \pm 0.02$ \\
\hline 2-pentylfuran & $4.70 \pm 0.21$ & $8.73 \pm 0.42$ & $4.91 \pm 0.12$ & $3.34 \pm 0.02$ \\
\hline Tot & $6.70 \pm 0.22$ & $17.57 \pm 0.20$ & $6.24 \pm 0.16$ & $5.43 \pm 0.04$ \\
\hline
\end{tabular}


Table 3. Cont.

\begin{tabular}{|c|c|c|c|c|}
\hline Sample/Elements & $\begin{array}{l}\text { Raw } \\
\text { GTW }\end{array}$ & $\begin{array}{l}\text { Raw } \\
\text { GSW }\end{array}$ & $\begin{array}{c}\text { GTW } \\
\text { Cooked in Unsalted } \\
\text { Water }\end{array}$ & $\begin{array}{c}\text { GSW } \\
\text { Cooked in Unsalted } \\
\text { Water }\end{array}$ \\
\hline \multicolumn{5}{|l|}{ Acids } \\
\hline Acetic acid & $3.58 \pm 0.11$ & $5.61 \pm 0.13$ & $\mathrm{Nd}$ & $\mathrm{Nd}$ \\
\hline 2-methylbutanoic acid & $0.24 \pm 0.01$ & $\mathrm{Nd}$ & $\mathrm{Nd}$ & $\mathrm{Nd}$ \\
\hline pentanoic acid & $\mathrm{Nd}$ & $0.48 \pm 0.03$ & $\mathrm{Nd}$ & $\mathrm{Nd}$ \\
\hline Hexanoic acid & $1.21 \pm 0.07$ & $1.88 \pm 0.01$ & $0.82 \pm 0.01$ & $\mathrm{Nd}$ \\
\hline Heptanoic acid & $0.41 \pm 0.02$ & $0.78 \pm 0.02$ & $0.24 \pm 0.01$ & $\mathrm{Nd}$ \\
\hline Octanoic acid & $0.53 \pm 0.01$ & $1.60 \pm 0.01$ & $\mathrm{Nd}$ & $\mathrm{Nd}$ \\
\hline Nonanoic acid & $0.53 \pm 0.02$ & $2.41 \pm 0.09$ & $\mathrm{Nd}$ & $\mathrm{Nd}$ \\
\hline Dodecanoic acid & $0.49 \pm 0.02$ & $\mathrm{Nd}$ & $\mathrm{Nd}$ & $\mathrm{Nd}$ \\
\hline Tetradecanoic acid & $1.32 \pm 0.09$ & $\mathrm{Nd}$ & $0.21 \pm 0.00$ & $\mathrm{Nd}$ \\
\hline Hexadecanoic acid & $3.21 \pm 0.13$ & $4.55 \pm 0.06$ & $0.22 \pm 0.00$ & $\mathrm{Nd}$ \\
\hline Tot & $11.51 \pm 0.23$ & $17.31 \pm 0.09$ & $1.49 \pm 0.00$ & $\mathrm{Nd}$ \\
\hline \multicolumn{5}{|l|}{ Terpenes } \\
\hline alpha pinene & $0.86 \pm 0.00$ & $1.42 \pm 0.04$ & $\mathrm{Nd}$ & $1.04 \pm 0.03$ \\
\hline delta 3-carene & $1.55 \pm 0.08$ & $3.35 \pm 0.14$ & $\mathrm{Nd}$ & $\mathrm{Nd}$ \\
\hline p-cymene & $\mathrm{Nd}$ & $0.68 \pm 0.02$ & $\mathrm{Nd}$ & $\mathrm{Nd}$ \\
\hline tot & $2.41 \pm 0.08$ & $5.45 \pm 0.08$ & $\mathrm{Nd}$ & $1.04 \pm 0.02$ \\
\hline \multicolumn{5}{|l|}{ Esters } \\
\hline Ethyl Acetate & $\mathrm{Nd}$ & $5.81 \pm 0.04$ & $\mathrm{Nd}$ & $\mathrm{Nd}$ \\
\hline Tot & $\mathrm{Nd}$ & $5.81 \pm 0.04$ & $\mathrm{Nd}$ & $\mathrm{Nd}$ \\
\hline \multicolumn{5}{|l|}{ Phenols } \\
\hline 3-ethylphenol & $0.31 \pm 0.01$ & $0.61 \pm 0.01$ & $\mathrm{Nd}$ & $\mathrm{Nd}$ \\
\hline Phenol & $0.08 \pm 0.00$ & $0.28 \pm 0.02$ & $0.25 \pm 0.02$ & $\mathrm{Nd}$ \\
\hline Tot & $0.38 \pm 0.01$ & $0.89 \pm 0.07$ & $0.25 \pm 0.02$ & $\mathrm{Nd}$ \\
\hline \multicolumn{5}{|l|}{ Terpenes } \\
\hline alpha pinene & $0.86 \pm 0.00$ & $1.42 \pm 0.04$ & $\mathrm{Nd}$ & $1.04 \pm 0.03$ \\
\hline delta 3 -carene & $1.55 \pm 0.08$ & $3.35 \pm 0.14$ & $\mathrm{Nd}$ & $\mathrm{Nd}$ \\
\hline p-cymene & $\mathrm{Nd}$ & $0.68 \pm 0.02$ & $\mathrm{Nd}$ & $\mathrm{Nd}$ \\
\hline Tot & $0.38 \pm 0.01$ & $0.89 \pm 0.07$ & $0.25 \pm 0.02$ & $\mathrm{Nd}$ \\
\hline
\end{tabular}

Results are reported as A\% = Area Peak Compound/Area Peak Total Compounds (A\% \pm SD), Nd (not detected).

\subsection{Thermogravimetric Analysis (TGA, DTG)}

In Figure 1a,b, TGA and derivative (DTG) thermograms of GTW samples before and after cooking are reported. All the curves were normalized with respect to starting sample weights.

\section{Gnocchi GTW before and after cooking}
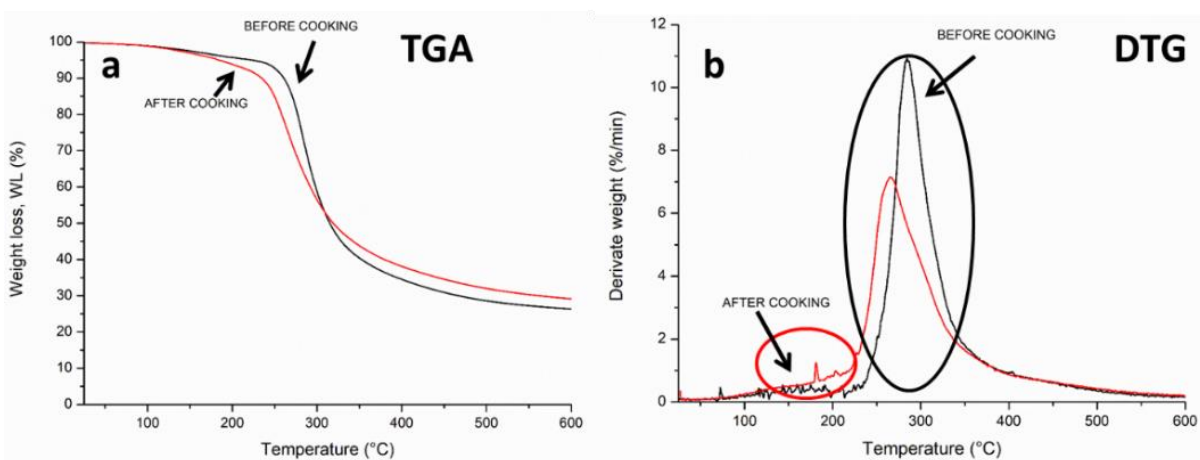

Figure 1. (a) TGA thermograms and (b) DTG curves of Gnocchi GTW before and after cooking.

From the analysis of GTW thermograms, it is possible to observe a lower water content after cooking (black curve). In fact, in Gnocchi dough, both starch and proteins are involved 
in physical interactions due to the presence of polar residues in both macromolecular structures; thus, starch and protein can form a gel when hydrated and heated and the gelling strength is influenced by several factors such as heating rate, holding time and temperature, $\mathrm{pH}$, ionic strength, minerals contents, all factors resulting in a complex physicochemical environment [42]. After starch-protein gelation, upon Gnocchi heating and cooling, a chemico-physical aggregation (hydrogen bonds, hydrophobic interaction, and Van der Waals forces) of the polymers occur, likely due to starch retrogradation, a process of recrystallization that takes place during food cooling and storage. In particular, after amylose releasing in boiling water, the branched amylopectin fraction, organizes in a tight and compact structure drastically reducing the available water binding sites. For this reason, as expected, the water content in cooked and cooled gnocchi is reduced (Figure 1a). The presence of amino acids influences starch pasting and retrogradation inducing a tight and strong physical network [43]. The main differences are correlated to the loss of food product quality, such as gnocchi staling, loss of viscosity, and of course, syneresis, as evidenced by Mohamed et al. [44]. Moreover, from the DTG curves (Figure 1b), it is possible to observe two thermal degradation phenomena: the first one is related to the water losing kinetics (red ring) at about $50-100{ }^{\circ} \mathrm{C}$ and the second one is due to starchprotein thermal degradation rate at around $300-350{ }^{\circ} \mathrm{C}$ [13]. No substantial differences can be found in the decomposition rate of the starch-protein macromolecular network of raw and cooked Gnocchi.

As far as GSW samples are concerned, different thermal profiles are reported for better highlighting their substantial differences before and after cooking. Indeed, both TGA and DTG thermograms are overlapped for raw (Figure 2a) and cooked (Figure 2b) GSW samples. Firstly, in both cases, three thermal degradation phenomena occurred: the first one was ascribed to water releasing in the range of 50-100 ${ }^{\circ} \mathrm{C}$ [45]; the second thermal step was associated with starch-protein decomposition (black ring); the third was correlated to salt decomposition at about $450-500{ }^{\circ} \mathrm{C}$ (green curve). In fact, from DTG curves, the maximum degradation rate of raw GSW starch-protein fraction occurred at $250{ }^{\circ} \mathrm{C}$, whereas the same phenomenon was shifted towards a substantially higher temperature $\left(300^{\circ} \mathrm{C}\right)$ for cooked GSW samples. Furthermore, a sharper single peak can be observed for cooked GSW samples; this outcome was in some way expected considering that the ionic and hydrogen bonding developed between sea water salts and polysaccharide and protein polar residues of potatoes and flour, resulted in a more tightened polymer network, highlighting a single pattern of degradation kinetics [46]. The higher stability of the polymer network in the cooked sample was due to the presence of the minerals enhancing the structural tightening. Thus, it is very probable that the micronutrients naturally occurring in sea water are preserved in GSW samples also after cooking, as confirmed by the micro/macro-nutrient analysis detailed in Table 2 and by the presence of salts thermal peak at around $500{ }^{\circ} \mathrm{C}$, far above the degradation kinetics of the polymer network. This outcome was confirmed by morphological analysis, as discussed in the following section.

\subsection{Scanning Electron Microscopy (SEM)}

The SEM micrographs of fractured surfaces of raw and cooked Gnocchi prepared with tap and sea water are reported in Figure 3. Gnocchi samples were cooked in unsalted water, in order to respect the right balance of dispersed inner ions and to correctly evaluate the morphological structure of GSW and GTW fractured surfaces. The micrographs related to raw (Figure 3a) and cooked (Figure 3b,c) GSW samples evidenced a tight structure of interconnected polymer regions homogeneously distributed. In fact, strong physical interactions occurred between the polar residues of starch, protein, and the ions naturally present in sea water, resulting in an optimal adhesion and stickiness of all the components, substantially different from the weak and labile network of samples cooked in salty water. It can be concluded that the sea water, used as a new ingredient of gnocchi dough improved their textural characteristics. Moreover, it is amazing to highlight that no substantial structural differences were observed before and after Gnocchi cooking, thus meaning that 
the physical binding resulted in a three-dimensional stable network in which mostly sea water macro-micro nutrients were preserved also after cooking at high temperature. This outcome both confirms the effectiveness of sea water as a protective agent of Gnocchi morphology, appearance and texture after the thermal treatment, and supports the previous findings of GSW higher thermal stability. Nevertheless, some small circular voids were observed both in raw and in cooked GSW samples, as evidenced in Figure 3c. They were likely due to the formation of some air bubbles during Gnocch $i$ kneading and preserved also after cooking, further confirming the strength of the GSW polymer network. As far as GTW samples are concerned, in Figure $3 \mathrm{~d}-\mathrm{f}$, the micrographs of raw (Figure $3 \mathrm{~d}$ ) and cooked (Figure $3 \mathrm{e}, \mathrm{f}$ ) samples are reported. A more heterogeneous and weaker network with the presence of irregular voids dispersed throughout the inner delaminated surface could be highlighted [47]. In particular, from the higher magnification of cooked GTW samples of Figure $3 \mathrm{f}$, discrete domains of higher material agglomeration were found, typical of a less tight and uneven polymer network [48]. In fact, during cooking, starch gelatinization and protein coagulation, occurring nearly at the same temperature, causes major structural changes resulting in textural hardness and stickiness loss.

\section{Gnocchi GSW before and after cooking}
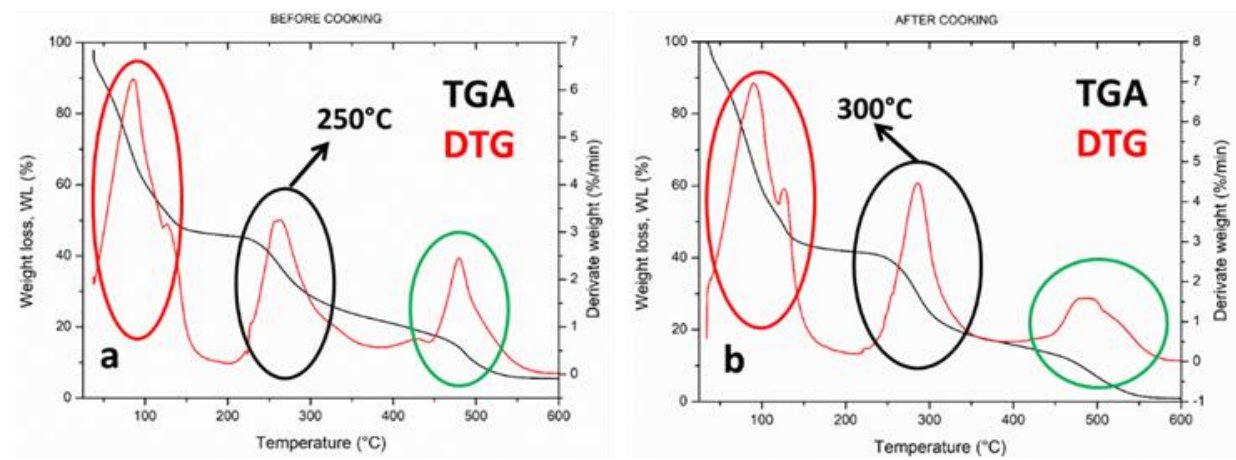

Figure 2. (a) TGA thermograms and (b) DTG curves of Gnocchi GSW before and after cooking.
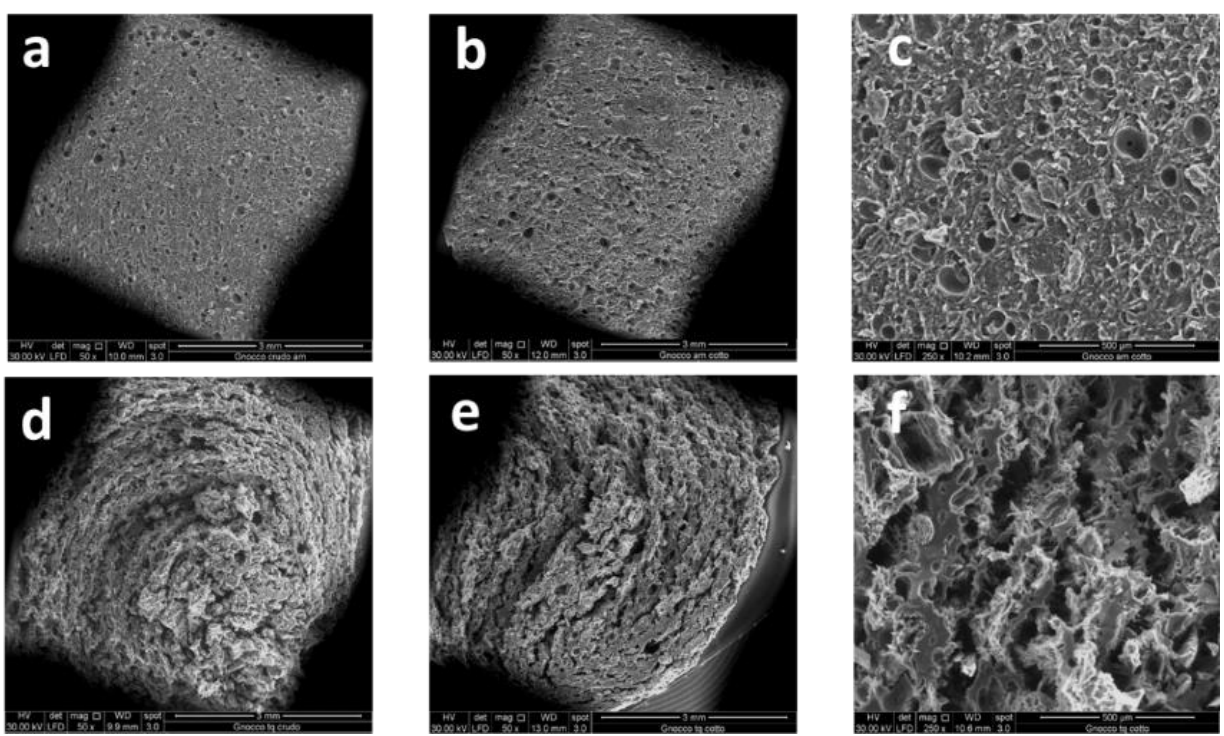

Figure 3. SEM micrographs of Gnocchi fractured surfaces: raw (a) and cooked in saline water (b,c) and raw (d) and cooked in tap water $(\mathbf{e}, \mathbf{f})$. 


\section{Conclusions}

This study evidenced that Gnocchi, one of the most loved and appreciated Italian dishes, kneaded with sea water represents a valuable option to obtain a novel functional food in which the enhanced nutritional and healthy micro-macro nutrients together with the higher profile of volatile molecules, confer high added value to the traditional Gnocchi prepared with tap water, providing a beneficial output for consumers and an interesting scientific approach finalized to obtain increasingly healthy foods.

The strongly decreasing sodium content, absolutely recommended from food guidelines for a healthy diet to reduce the risk of serious health diseases, represents a challenging and terrific strong point in the use of the active ingredient. Subsequent evaluations with a trained panel will also highlight the sensorial aspects of gnocchi kneaded with sea water in order to evaluate the influence of the novel ingredient and cooking process on the tasty and palatable acceptability of the finished product, highly important for the food and gastronomy sciences community.

Author Contributions: In this paper, the authors synergically assisted the main steps of the research, leading to the final version of the manuscript. In particular, M.G.V. was devoted to the theoretical investigation, conceptualization, coordination and writing of the original draft of the paper; G.S. was particularly engaged in the planning joint research activities, writing, reviewing and editing of the paper; D.Z., S.M. and F.B. equally contributed to the experimental analysis, data curation and their validation and to the discussion of the results M.G.V. and G.S. contributed to the supervision and project management. All authors have read and agreed to the published version of the manuscript.

Funding: The present work has been partially supported by CNR project NUTR-AGE (FOE-2019, DSB.AD004.271).

Data Availability Statement: Not Applicable.

Acknowledgments: The authors would like to thank Pastificio Artigianale Leonessa, Napoli (Italy) for providing Gnocchi samples, Asset Committee srl, Portici, Napoli (Italy), for kindly supplying the sea water produced from Abba Blu srl (San Sperate CA Italy). The authors also thank Maria Cristina Del Barone for the valid support in the technical assistance of morphological analysis, performed at Laboratory of Scanning and Transmission electron Microscopy (LAMeST), "Augusto Sirigu" of Institute for Polymers, Composites and Biomaterials and il Francesco Siano of Isa-Cnr for the valid support in the technical assistance of chemical analysis.

Conflicts of Interest: The authors declare no conflict of interest.

\section{References}

1. Ríos, D.; Ghislain, M.; Rodríguez, F.; Spooner, D.M. What Is the Origin of the European Potato? Evidence from Canary Island Landraces. Crop. Sci. 2007, 47, 1271-1280. [CrossRef]

2. Alessandrini, L.; Balestra, F.; Romani, S.; Rocculi, P.; Rosa, M.D. Physicochemical and Sensory Properties of Fresh Potato-Based Pasta (Gnocchi). J. Food Sci. 2010, 75, S542-S547. [CrossRef] [PubMed]

3. Ozkayar, N.; Dede, F.; Ates, I.; Akyel, F.; Yildirim, T.; Altun, B. The Relationship between Dietary Salt Intake and Ambulatory Blood Pressure Variability in Non-Diabetic Hypertensive Patients. Nefrología 2016, 36, 694-700. [CrossRef]

4. He, F.J.; Tan, M.; Ma, Y.; MacGregor, G.A. Salt Reduction to Prevent Hypertension and Cardiovascular Disease. J. Am. Coll. Cardiol. 2020, 75, 632-647. [CrossRef]

5. He, FJ.; MacGregor, G.A. 2-Dietary salt, high blood pressure and other harmful effects on health. In Reducing Salt in Foods; Kilcast, D., Angus, F., Eds.; Woodhead Publishing Series in Food Science; Technology and Nutrition; Woodhead Publishing: Cambridge, UK, 2007; pp. 18-54, ISBN 978-1-84569-018-2.

6. Balasubramanian, A. Properties of Seawater. 2011. Available online: https://www.researchgate.net/publication/309785723_ Properties_of_Seawater-Documentary (accessed on 20 October 2021). [CrossRef]

7. Loganathan, P.; Naidu, G.; Vigneswaran, S. Mining Valuable Minerals from Seawater: A Critical Review. Environ. Sci. Water Res. Technol. 2017, 3, 37-53. [CrossRef]

8. Volpe, M.G.; Nazzaro, M.; Coppola, R.; Rapuano, F.; Aquino, R.P. Determination and Assessments of Selected Heavy Metals in Eye Shadow Cosmetics from China, Italy, and USA. Microchem. J. 2012, 101, 65-69. [CrossRef]

9. di Renzo, T.; Reale, A.; Boscaino, F.; Messia, M.C. Flavoring Production in Kamut ${ }^{\circledR}$, Quinoa and Wheat Doughs Fermented by Lactobacillus Paracasei, Lactobacillus Plantarum, and Lactobacillus Brevis: A SPME-GC/MS Study. Front. Microbiol. 2018, 9, 429. [CrossRef] [PubMed] 
10. Vyazovkin, S.; Chrissafis, K.; Di Lorenzo, M.L.; Koga, N.; Pijolat, M.; Roduit, B.; Sbirrazzuoli, N.; Suñol, J.J. ICTAC Kinetics Committee Recommendations for Collecting Experimental Thermal Analysis Data for Kinetic Computations. Thermochim. Acta 2014, 590, 1-23. [CrossRef]

11. Nešić, A.; Onjia, A.; Davidović, S.; Dimitrijević, S.; Errico, M.E.; Santagata, G.; Malinconico, M. Design of Pectin-Sodium Alginate Based Films for Potential Healthcare Application: Study of Chemico-Physical Interactions between the Components of Films and Assessment of Their Antimicrobial Activity. Carbohydr. Polym. 2017, 157, 981-990. [CrossRef]

12. Moeini, A.; Cimmino, A.; Poggetto, G.D.; Biase, M.D.; Evidente, A.; Masi, M.; Lavermicocca, P.; Valerio, F.; Leone, A.; Santagata, G.; et al. Effect of PH and TPP Concentration on Chemico-Physical Properties, Release Kinetics and Antifungal Activity of Chitosan-TPP-Ungeremine Microbeads. Carbohydr. Polym. 2018, 195, 631-641. [CrossRef]

13. Turco, R.; Ortega-Toro, R.; Tesser, R.; Mallardo, S.; Collazo-Bigliardi, S.; Chiralt Boix, A.; Malinconico, M.; Rippa, M.; Serio, M.D.; Santagata, G. Poly (Lactic Acid)/Thermoplastic Starch Films: Effect of Cardoon Seed Epoxidized Oil on Their Chemicophysical, Mechanical, and Barrier Properties. Coatings 2019, 9, 574. [CrossRef]

14. Donmez, D.; Pinho, L.; Patel, B.; Desam, P.; Campanella, O.H. Characterization of Starch-Water Interactions and Their Effects on Two Key Functional Properties: Starch Gelatinization and Retrogradation. Curr. Opin. Food Sci. 2021, 39, 103-109. [CrossRef]

15. Wang, L.; Zhang, L.; Wang, H.; Ai, L.; Xiong, W. Insight into Protein-Starch Ratio on the Gelatinization and Retrogradation Characteristics of Reconstituted Rice Flour. Int. J. Biol. Macromol. 2020, 146, 524-529. [CrossRef] [PubMed]

16. Razzaq, H.A.A.; Gomez d'Ayala, G.; Santagata, G.; Bosco, F.; Mollea, C.; Larsen, N.; Duraccio, D. Bioactive Films Based on Barley $\beta$-Glucans and $\mathrm{ZnO}$ for Wound Healing Applications. Carbohydr. Polym. 2021, 272, 118442. [CrossRef]

17. Sozer, N.; Kaya, A. The Effect of Cooking Water Composition on Textural and Cooking Properties of Spaghetti. Int. J. Food Prop. 2008, 11, 351-362. [CrossRef]

18. Kloss, L.; Meyer, J.D.; Graeve, L.; Vetter, W. Sodium Intake and Its Reduction by Food Reformulation in the European Union-A Review. NFS J. 2015, 1, 9-19. [CrossRef]

19. Gie Liem, D.; Miremadi, F.; J Keast, R.S. Reducing Sodium in Foods: The Effect on Flavor. Nutrients 2011, 3, 694-711. [CrossRef] [PubMed]

20. Sharif, M.K.; Butt, M.S.; Sharif, H.R.; Nasir, M. Sensory Evaluation and Consumer Acceptability. Handb. Food Sci. Technol. 2017, 3, 362-386.

21. Moeini, A.; Mallardo, S.; Cimmino, A.; Poggetto, G.D.; Masi, M.; Biase, M.D.; van Reenen, A.; Lavermicocca, P.; Valerio, F.; Evidente, A.; et al. Thermoplastic Starch and Bioactive Chitosan Sub-Microparticle Biocomposites: Antifungal and ChemicoPhysical Properties of the Films. Carbohydr. Polym. 2020, 230, 115627. [CrossRef] [PubMed]

22. Moeini, A.; Germann, N.; Malinconico, M.; Santagata, G. Formulation of Secondary Compounds as Additives of BiopolymerBased Food Packaging: A Review. Trends Food Sci. Technol. 2021, 114, 342-354. [CrossRef]

23. Delcour, J.A.; Vansteelandt, J.; Hythier, M.-C.; Abécassis, J. Fractionation and Reconstitution Experiments Provide Insight into the Role of Starch Gelatinization and Pasting Properties in Pasta Quality. J. Agric. Food Chem. 2000, 48, 3774-3778. [CrossRef] [PubMed]

24. Houston, M.C.; Harper, K.J. Potassium, Magnesium, and Calcium: Their Role in Both the Cause and Treatment of Hypertension. J. Clin. Hypertens. 2008, 10, 3-11. [CrossRef] [PubMed]

25. Crook, M. Handbook of Toxicologic Pathology, 2nd ed.; Haschek, W.M., Rousseaux, C.G., Wallig, M.A., Eds.; Academic Press: Cambridge, MA, USA, 2001; ISBN 0123302153.

26. Nalepa, B.; Siemianowska, E.; Skibniewska, K.A. Influence of Bifidobacterium Bifidum on Release of Minerals from Bread with Differing Bran Content. J. Toxicol. Environ. Heal. Part A 2012, 75, 1-5. [CrossRef]

27. Witkowski, M.; Hubert, J.; Mazur, A. Methods of Assessment of Magnesium Status in Humans: A Systematic Review. Magnes. Res. 2011, 24, 163-180. [CrossRef] [PubMed]

28. De Baaij, J.H.F.; Hoenderop, J.G.J.; Bindels, R.J.M. Magnesium in Man: Implications for Health and Disease. Physiol. Rev. 2015, 95, 1-46. [CrossRef]

29. Stone, M.S.; Martyn, L.; Weaver, C.M. Potassium Intake, Bioavailability, Hypertension, and Glucose Control. Nutrients 2016, 8 , 444. [CrossRef]

30. Kaur, K.; Gupta, R.; Saraf, S.A.; Saraf, S.K. Zinc: The Metal of Life. Compr. Rev. Food Sci. Food Saf. 2014, 13, 358-376. [CrossRef]

31. Prasad, A.S.; Bao, B.; Beck, F.W.J.; Kucuk, O.; Sarkar, F.H. Antioxidant Effect of Zinc in Humans. Free. Radic. Biol. Med. 2004, 37, 1182-1190. [CrossRef]

32. Osredkar, J. Copper and Zinc, Biological Role and Significance of Copper/Zinc Imbalance. J. Clin. Toxicol. 2011, s3, 1-18. [CrossRef]

33. Al-MussaliI, M.S.; Al-Gahri, M.A. Nutritive Value of Commonly Consumed Bread in Yemen. E-J. Chem. 1900, 6, 975960. [CrossRef]

34. Głąbska, D.; Malowaniec, E.; Guzek, D. Validity and Reproducibility of the Iodine Dietary Intake Questionnaire Assessment Conducted for Young Polish Women. Int. J. Environ. Res. Public Health 2017, 14, 700. [CrossRef]

35. Zimmermann, M.B.; Jooste, P.L.; Pandav, C.S. Iodine-Deficiency Disorders. Lancet 2008, 372, 1251-1262. [CrossRef]

36. Alexander, J.; Benford, D.; Cockburn, A.; Cravedi, J.-P.; Dogliotti, E.; di Domenico, A.; Férnandez-Cruz, M.L.; Fürst, P.; FinkGremmels, J.; Galli, C.L.; et al. Cadmium in Food-Scientific Opinion of the Panel on Contaminants in the Food Chain. EFSA J. 2009, 980, 1-139. [CrossRef]

37. Panel, E.; Chain, F. Scientific Opinion on Lead in Food. EFSA J. 2010, 8, 1-151. [CrossRef] 
38. Giannetti, V.; Boccacci Mariani, M.; Mannino, P.; Testani, E. Furosine and Flavour Compounds in Durum Wheat Pasta Produced under Different Manufacturing Conditions: Multivariate Chemometric Characterization. LWT_Food Sci. Technol. 2014, 56, 15-20. [CrossRef]

39. Dresow, J.F.; Böhm, H. The Influence of Volatile Compounds of the Flavour of Raw, Boiled and Baked Potatoes: Impact of Agricultural Measures on the Volatile Components. Landbauforsch. Volkenrode 2009, 59, 309-338.

40. Beleggia, R.; Platani, C.; Spano, G.; Monteleone, M.; Cattivelli, L. Metabolic Profiling and Analysis of Volatile Composition of Durum Wheat Semolina and Pasta. J. Cereal Sci. 2009, 49, 301-309. [CrossRef]

41. Kermasha, S.; van de Voort, F.R.; Metche, M. Changes in Carbonyl Compounds in the French Bean as a Function of Cooking and Enzyme Treatment. J. Agric. Food Chem. 1988, 36, 133-137. [CrossRef]

42. Yang, N.; Luan, J.; Ashton, J.; Gorczyca, E.; Kasapis, S. Effect of Calcium Chloride on the Structure and in Vitro Hydrolysis of Heat Induced Whey Protein and Wheat Starch Composite Gels. Food Hydrocoll. 2014, 42, 260-268. [CrossRef]

43. Hu, Y.; He, C.; Zhang, M.; Zhang, L.; Xiong, H.; Zhao, Q. Inhibition from Whey Protein Hydrolysate on the Retrogradation of Gelatinized Rice Starch. Food Hydrocoll. 2020, 108, 105840. [CrossRef]

44. Mohamed, I.O. Effects of Processing and Additives on Starch Physicochemical and Digestibility Properties. Carbohydr. Polym. Technol. Appl. 2021, 2, 100039. [CrossRef]

45. Zannini, D.; Dal Poggetto, G.; Malinconico, M.; Santagata, G.; Immirzi, B.; Klapiszewski, Ł. Citrus Pomace Biomass as a Source of Pectin and Lignocellulose Fibers: From Waste to Upgraded Biocomposites for Mulching Applications. Polymers 2021, $13,1280$. [CrossRef] [PubMed]

46. Azevedo, V.M.; Borges, S.V.; Marconcini, J.M.; Yoshida, M.I.; Neto, A.R.S.; Pereira, T.C.; Pereira, C.F.G. Effect of Replacement of Corn Starch by Whey Protein Isolate in Biodegradable Film Blends Obtained by Extrusion. Carbohydr. Polym. 2017, 157, 971-980. [CrossRef] [PubMed]

47. Turco, R.; Tesser, R.; Cucciolito, M.E.; Fagnano, M.; Ottaiano, L.; Mallardo, S.; Malinconico, M.; Santagata, G.; Di Serio, M. Cynara Cardunculus Biomass Recovery: An Eco-Sustainable, Nonedible Resource of Vegetable Oil for the Production of Poly(Lactic Acid) Bioplasticizers. ACS Sustain. Chem. Eng. 2019, 7, 4069-4077. [CrossRef]

48. Turco, R.; Zannini, D.; Mallardo, S.; Dal Poggetto, G.; Tesser, R.; Santagata, G.; Malinconico, M.; Di Serio, M. Biocomposites Based on Poly(Lactic Acid), Cynara Cardunculus Seed Oil and Fibrous Presscake: A Novel Eco-Friendly Approach to Hasten PLA Biodegradation in Common Soil. Polym. Degrad. Stab. 2021, 188, 109576. [CrossRef] 